\title{
Near-fatal systemic oxygen embolism due to wound irrigation with hydrogen peroxide
}

\author{
MAYER M. BASSAN \\ M.D. \\ MOSHE DUDAI \\ M.D. \\ ODED SHALEV
}

The Intensive Care Unit, Department of Internal Medicine, Hadassah-Hebrew University Medical Center, Mt Scopus, Jerusalem, Israel

\begin{abstract}
Summary
Shock and coma developed suddenly in a 54-year-old male undergoing irrigation of an infected and fistulous herniorrhaphy wound with $3 \%$ hydrogen peroxide $\left(\mathrm{H}_{2} \mathrm{O}_{2}\right)$. Marked ST elevation was seen in almost all electrocardiogram (ECG) leads. Within one hour the patient recovered completely, and the ECG returned to normal. The mechanism of this occurrence was most likely widespread embolization of oxygen microbubbles released from absorbed $\mathrm{H}_{2} \mathrm{O}_{2}$. The danger of hydrogen peroxide irrigation in closed spaces is emphasized.
\end{abstract}

\section{Introduction}

Hydrogen peroxide solution is used extensively in the cleansing of wounds. When hydrogen peroxide is applied to tissue, catalase causes its rapid decomposition with the release of bubbles of molecular oxygen. These have a slight germicidal effect and cause some mechanical removal of tissue debris (Goodman and Gilman, 1975).

Administration of hydrogen peroxide into closed spaces or body cavities from which the released oxygen has no free egress may have various dangerous effects. Facial emphysema has been described following irrigation with hydrogen peroxide during endodontic treatment (Bhat, 1974), and death has been reported following ingestion of a concentrated solution by a toddler (Giusti, 1973). Oxygen embolization to the mesenteric and portal veins has been reported in several infants following intestinal irrigation with hydrogen peroxide to remove inspissated meconium (Danis, Brodeur and Shields, 1967; Shaw, Cooperman and Fusco, 1967). In one of these cases

Address for correspondence: Dr Mayer M. Bassan, Hadassah University Hospital-Mt Scopus, PO Box 24035, il-91240 Jerusalem, Israel. death resulted from gangrene of the bowel (Shaw $e t$ al., 1967). We report the case of an adult who suffered near-fatal systemic oxygen embolism following wound irrigation with hydrogen peroxide.

\section{Case report}

An obese 54-year-old male was seen in the emergency room complaining of pain and discharge from the surgical wound of a right inguinal herniorrhaphy. The original surgery had been performed 3 weeks earlier and had been complicated by a wound infection. On examination an area of fluctuation was palpated lateral to the wound, extending in the direction of the flank. By means of blunt dissection, a connection was established between the opening of the wound and the fluctuant cavity, creating a tract. The combined length of the tract and the cavity was about $20 \mathrm{~cm}$, and the diameter narrowed from $4 \mathrm{~cm}$ in the cavity to $1 \mathrm{~cm}$ in the tract. Approximately 20 $\mathrm{ml}$ of cloudy fluid were drained. The walls of the cavity were curretted with the appearance of slight bleeding, and an $18 \mathrm{~F}$ Nelaton catheter was inserted and connected to an irrigating syringe. Irrigation was carried out under pressure using a 3\% hydrogen peroxide solution in $20 \mathrm{ml}$ volumes, and in retrospect it was recalled that not all the irrigating volume seemed to have drained from the wound. During the first several $20 \mathrm{ml}$ irrigations the patient complained of a burning pain in the wound. During the fifth irrigation it was suddenly realized that the patient had stopped complaining, and when asked how he was feeling, there was no response. His gaze was noted to be fixed, and several seconds later his eyeballs deviated up and to the right. His skin became grey, pale, cool and clammy, and his breathing was slow and deep. Peripheral pulses were 


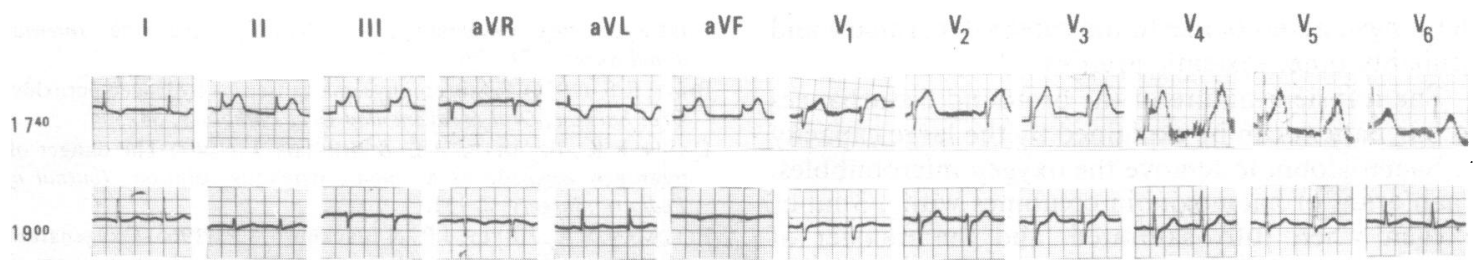

FIG. 1. Serial ECG tracings. 17.40 hours, 10 mins after the onset of coma. Note ST elevation in II, III, AVF, and $\mathrm{V}_{1}-\mathrm{V}_{6}$, indicative of inferior and anterior myocardial injury/ischaemia. 19.00 hours, complete resolution.

not palpable. Within several minutes pulses returned, and a systolic blood pressure of $85 \mathrm{mmHg}$ was measured. An electrocardiogram (ECG) (Fig. 1, 17.40 hours) revealed ST segment elevation in leads II, III, AVF and $V_{1}$ through $V_{6}$.

Irrigation was discontinued and as much of the solution as possible was aspirated from the wound. One gram of hydrocortisone and $44 \mathrm{mmol}$ of sodium bicarbonate were given intravenously. The patient remained in a deep coma with generalized rigidity for a total of 15 mins. The rigidity then disappeared, and spontaneous directed arm movements began.

The patient was transferred to the intensive care unit where a blood pressure of $110 / 85 \mathrm{mmHg}$ was recorded, and an ECG showed almost complete disappearance of the ST segment elevations. The patient regained consciousness, and within 40 mins of the beginning of the episode no neurological deficit could be found. Fundoscopy revealed no intravascular gas bubbles or haemorrhages. The patient complained of mild headache and fatigue and was totally amnesic with regard to the events of the preceeding hour. An electrocardiogram (Fig. 1, $1900 \mathrm{hr}$ ) taken one hour later showed no ST segment elevation, and serial serum glutamic oxaloacetic transaminase and creatine-kinase determinations over the following two days were within normal limits. Blood tested for methaemoglobin was negative, free haemoglobin was $40 \mathrm{~g} / \mathrm{dl}$ and there was no fall in haematocrit. Recovery was full and uneventful, and the patient was discharged 3 days after the episode.

\section{Discussion}

It seems clear that the near-fatal episode suffered by the patient was due to the irrigation of the closed space with hydrogen peroxide. In the absence of red cell damage or methaemoglobin formation, and because of the clinical and ECG evidence of profound transient neurologic and cardiac dysfunction, it appears most likely that widespread systemic embolization of oxygen microbubbles occurred, especially to the cerebral and coronary arteries. The questions posed by this hypothesis are whether or not significant local absorption of hydrogen peroxide or oxygen bubbles into the vascular system can take place, and if so can the oxygen bubbles cross the lungs and cause systemic embolism?

Most of the knowledge concerning the adverse effects of intravascular hydrogen peroxide has come from research designed to evaluate its administration as a means of extrapulmonary oxygenation. Such oxygenation was first attempted in 1919 by the intravenous injection of hydrogen peroxide in patients with severe influenzal pneumonia (Oliver and Murphy, 1920). It was recognized then that the obvious danger was gas embolism. One $\mathrm{ml}$ of $3 \%$ $\mathrm{H}_{2} \mathrm{O}_{2}$ releases $10 \mathrm{ml}$ of oxygen upon decomposition following contact with catalase, which is present in abundance in human blood (Fuson et al., 1967).

Animal investigations have shown that hydrogen peroxide is readily absorbed from sites such as intestine (Yun, 1969) and peritoneum (Awad et al., 1970) producing oxygen bubbles. In humans, intestinal absorption of hydrogen peroxide has been demonstrated following administration by enema (Yun, 1969) as well as following intestinal irrigation to remove mectonium (Danis et al., 1967; Shaw et al., 1967). In one case (Shaw et al., 1967), oxygen bubbles were seen in the mesenteric vessels, while in the other (Danis et al., 1967), they were seen in the portal vein as well. In cats and rabbits, these bubbles were shown to be capable of traversing the liver and the lungs and causing emboli in the coronary arteries (Awad et al., 1970). Additional evidence that the bubbles can traverse the lungs was demonstrated by the administration of $3 \% \mathrm{H}_{2} \mathrm{O}_{2}$ into the right ventricle of the pig resulting in systemic embolism (Fuson et al., 1967). Infusion of $3 \% \mathrm{H}_{2} \mathrm{O}_{2}$ into the descending aorta of the apnoeic cat at too rapid a rate led to bubble formation, with ischaemic ECG changes and hypotension (Feldman, Hoyle and Blackburn, 1966) due to return of the bubbles through the venous system of the lower part of the body to the heart.

Based on these observations in humans and animals we assume that irrigation under pressure of the bleeding, friable tissue in the semi-closed space of our patient's wound led to absorption of a significant amount of hydrogen peroxide and/or oxygen bubbles. Large quantities of oxygen microbubbles reached the venous system and were able to traverse 
the lungs and embolize to the cerebral, coronary and probably other systemic arteries.

The transient nature of the profound disturbances in our patient can be explained by the large capacity of haemoglobin to remove the oxygen microbubbles. Each gram of haemoglobin combines with $1.3 \mathrm{ml}$ of oxygen when fully saturated, and the transfer of oxygen to haemoglobin from hydrogen peroxide added to human blood has been shown to be almost $100 \%$ efficient (White and Teasdale, 1966). Assuming our patient may have absorbed as much as $20 \mathrm{ml}$ of $3 \%$ hydrogen peroxide, or the equivalent in oxygen bubbles, approximately $200 \mathrm{ml}$ of oxygen bubbles would have been formed. If oxygen consumption is of the order of $250 \mathrm{ml} / \mathrm{min}$ (Guyton, 1976) and only $20 \%$ were obtained from the oxygen microbubbles, the total amount would be consumed within several minutes.

Our case serves to emphasize the danger of irrigation with hydrogen peroxide in situations where owing to lack of free exit, systemic absorption of peroxide and/or oxygen bubbles may occur.

\section{References}

Awad, J.A., Brassard, A., Caron, W. \& Cadrin, C. (1970)
Intraperitoneal oxygenation with hydrogen peroxide. International Surgery 54, 276.

BHAT, K.S. (1974) Tissue emphysema caused by hydrogen peroxide. Oral Surgery, Oral Medicine and Oral Pathology, 38, 304.

DANiS, R.K., BRodeUR, A.E. \& ShIEldS, J. (1967) The danger of hydrogen peroxide as a colonic irrigating solution. Journal of Pediatric Surgery, 2, 131.

FeldMAN, S.A., HoYLE, J.R. \& Blackburn, J.P. (1966) Oxygenation of cats by hydrogen peroxide during temporary ventilatory arrest. British Medical Journal, 2, 28.

Fuson, R.L., Kylstra, J.A., Hochstein, P. \& Saltzman, H.A. (1967) Intravenous hydrogen peroxide infusion as a means of extrapulmonary oxygenation. Clinical Research, 15, 74.

GIUSTI, G.V. (1973) Fatal poisoning with hydrogen peroxide. Forensic Science, 2, 99.

Goodman, L.S. \& Gilman, A. (1975) The Pharmacological Basis of Therapeutics. 5th edn. p. 997. Macmillan Publishing Co. Inc. New York.

GuYTON, A.C. (1976) Textbook of Medical Physiology, p. 550. W.B. Saunders, Philadelphia.

OLIVER, T.H. \& MURPHY, D.V. (1920) Influenzal pneumonia: the intravenous injection of hydrogen peroxide. Lancet, i, 432.

Shaw, A., Cooperman, A. \& Fusco, J. (1967) Gas embolism produced by hydrogen peroxide. New England Journal of Medicine, $277,238$.

WhITE, D.C. \& Teasdale, P.R. (1966) The oxygenation of blood by hydrogen peroxide; in vitro studies. British Journal of Anaesthesia, 38, 339.

YUN, D.J. (1969) Extrapulmonary oxygenation by giving hydrogen peroxide by enema. Yonsei Medical Journal, 2, 125. 